\title{
Recognition of an Avr3a Homologue Plays a Major Role in Mediating Nonhost Resistance to Phytophthora capsici in Nicotiana Species
}

\author{
Julio C. Vega-Arreguín, ${ }^{1,2}$ Abubakar Jalloh, ${ }^{1,3}$ Jorunn I. Bos, ${ }^{4,5}$ and Peter Moffett ${ }^{1,6}$ \\ ${ }^{1}$ Boyce Thompson Institute for Plant Research, Ithaca, NY, 14850, U.S.A.; ${ }^{2}$ Universidad Nacional Autónoma de México, \\ ENES Unidad León. León, Gto. México; ${ }^{3}$ Department of Molecular Biology and Genetics, Cornell University, Ithaca, NY, \\ 14850, U.S.A.; ${ }^{4}$ The James Hutton Institute, Errol Road, Invergowrie, Dundee DD2 5DA, Scotland, U.K.; ${ }^{5}$ University of Dundee, \\ Division of Plant Sciences, University of Dundee, Dundee DD2 5DA, U.K.; ${ }^{6}$ Département de Biologie, Faculté des Sciences, \\ Université de Sherbrooke, Sherbrooke, Québec, Canada
}

Submitted 23 January 2014. Accepted 31 March 2014.

\begin{abstract}
Nonhost resistance is a commonly occurring phenomenon wherein all accessions or cultivars of a plant species are resistant to all strains of a pathogen species and is likely the manifestation of multiple molecular mechanisms. Phytophthora capsici is a soil-borne oomycete that causes Phytophthora blight disease in many solanaceous and cucurbitaceous plants worldwide. Interest in $\boldsymbol{P}$. capsici has increased considerably with the sequencing of its genome and its increasing occurrence in multiple crops. However, molecular interactions between $P$. capsici and both its hosts and its nonhosts are poorly defined. We show here that tobacco (Nicotiana tabacum) acts like a nonhost for $P$. capsici and responds to $P$. capsici infection with a hypersensitive response (HR). Furthermore, we have found that a $P$. capsici Avr3a-like gene (PcAvr3a1) encoding a putative RXLR effector protein produces a HR upon transient expression in tobacco and several other Nicotiana species. This HR response correlated with resistance in 19 of 23 Nicotiana species and accessions tested, and knock-down of PcAvr3a1 expression by host-induced gene silencing allowed infection of resistant tobacco. Our results suggest that many Nicotiana species have the capacity to recognize PcAvr3a1 via the products of endogenous disease resistance $(R)$ genes and that this $R$ gene-mediated response is a major component of nonhost resistance to $P$. capsici.
\end{abstract}

Nonhost resistance is broadly defined as a situation in which all accessions of a given plant species are resistant to all isolates of a given pathogen (Thordal-Christensen 2003). The mechanisms by which nonhost resistance is mediated, however, are likely numerous (Schulze-Lefert and Panstruga 2011). These may include structural barriers, including waxy cuticles and cell walls, as well as plant-produced antimicrobial compounds. Once past these barriers, pathogens encounter the plant innate immune system. Like most multi-cellular organisms, plants have evolved to recognize pathogen-associated molecular patterns (PAMPs),

Corresponding author: P. Moffett; Email: Peter.Moffett@USherbrooke.ca; Telephone: +1 819 821-8000, ext. 61057 Fax: +1 819 821-8049.

* The $\boldsymbol{e}$-Xtra logo stands for "electronic extra" and indicates that four supplementary figures and one supplementary table are published online.

(C) 2014 The American Phytopathological Society highly conserved molecules that are associated with broad groups of pathogens (Ausubel 2005). PAMPs are recognized by plant pattern recognition receptors (PRR), often receptor-like kinases that, in turn, activate what is known as PAMP-triggered immunity (PTI) (Chisholm et al. 2006; Segonzac and Zipfel 2011; Zipfel 2009). PTI responses are generally "low-impact," preventing the proliferation of the pathogen in the apoplast with few or no macroscopic symptoms (Gohre and Robatzek 2008; Jones and Dangl 2006). Host-adapted pathogens have evolved to overcome PTI by secreting so-called effector proteins into the host cytoplasm, many of which are known to interfere with components of PTI signaling pathways (Gohre and Robatzek 2008; Segonzac and Zipfel 2011; Win et al. 2012; Zipfel 2009). In turn, effector proteins can be recognized by the plant and induce the activation of effector-triggered immunity (ETI), in which case they have traditionally been referred to as avirulence (Avr) proteins (Chisholm et al. 2006; Jones and Dangl 2006). ETI is mediated by the products of disease resistance $(R)$ genes that recognize pathogen-encoded proteins that are usually specific to a particular pathogen or pathogen race. $\mathrm{R}$ proteins induce a much more dramatic response than PRR, often culminating in a type of cell death known as the hypersensitive response (HR) (Jones and Dangl 2006). The majority of characterized $R$ genes encode nucleotide binding leucine-rich repeat (NB-LRR) proteins, which possess $\mathrm{NB}$ and LRR domains (McHale et al. 2006). The Avr proteins recognized by NB-LRR proteins, on the other hand, show little commonality except that they are delivered to the host cytoplasm by the various delivery systems of plant pathogens (Alfano and Collmer 2004; Soanes and Talbot 2008).

Effector proteins are delivered into host cells by the pathogen to modulate plant defense responses and enable parasitic colonization (Birch et al. 2006; Chisholm et al. 2006; Grant et al. 2006; Jones and Dangl 2006; Kamoun 2006; O'Connell and Panstruga 2006). Plant pathogenic oomycetes encode for complex and diverse sets of RXLR effector proteins that have undergone relatively rapid birth and death evolution (Win et al. 2007). Oomycete RXLR effectors are modular proteins, with the N-terminus encompassing the signal peptide and RXLR leader and involved in secretion and translocation to the host cytoplasm, and the $\mathrm{C}$-terminal domain dedicated to modulating host defenses inside plant cells (Bos et al. 2010; Dou et al. 2008a Kamoun 2006; Whisson et al. 2007; Win et al. 2007). Indeed, positive selection appears to have acted largely on the C-terminal region of paralogous RXLR gene families (Morgan 
and Kamoun 2007; Win et al. 2007). Furthermore, the RXLR motif is not required for the effector activities of Phytophthora infestans Avr3a when this protein is directly expressed inside plant cells, consistent with a role in targeting rather than effector activity (Bos et al. 2006).

Phytophthora capsici is an oomycete pathogen with a broad host range, causing Phytophthora blight in many solanaceous, cucurbit, and bean crops worldwide (Hausbeck and Lamour 2004; Lamour et al. 2011, 2012a) as well as a number of weed species (French-Monar 2006). In addition, . capsici has been shown to infect a number of other plants under laboratory conditions (Tian and Babadoost 2004). The recent sequencing of its genome has allowed for the identification of over 350 candidate RXLR effectors (Lamour et al. 2007, 2011, 2012b). However, the individual roles of these candidate RXLR effector genes in interactions with host and nonhost plants are largely unknown. We hypothesized that some of these effector proteins may be recognized by the products of plant $R$ genes and that this recognition may form the basis of nonhost resistance in certain plants not normally infected by $P$. capsici. We also reasoned that if an effector is recognized in one host-pathogen interaction then well-conserved homologs thereof present in other pathogens might likewise be recognized in host or nonhost plants or both.

The Avr3a gene from $P$. infestans confers avirulence on potato plants expressing the $R 3 a$ gene, which encodes a typical NBLRR protein (Armstrong et al. 2005). In addition, Avr3a suppresses cell death induced by the $P$. infestans elicitin protein INF1 and interacts with and stabilizes the host ubiquitin E3 ligase CMPG1, pointing to a possible virulence function (Bos et al. 2006, 2010). Likewise, Avrlb, a homolog of $A v r 3 a$, is present in the soybean pathogen $P$. sojae and confers avirulence in soybean plants expressing the Rps 1 b gene (Shan et al. 2004).
In this study, we have found that a number of Nicotiana species, including Nicotiana tabacum, appear to be nonhosts for $P$. capsici and respond to $P$. capsici zoospores with a HR. Moreover, we have found that a $P$. capsici RXLR effector, PcAvr3a1, shows avirulence function in these same species. In testing a number of Nicotiana species for PcAvr3a1-induced $\mathrm{HR}$, we found all species that responded to PcAvr3a1 with a HR also showed resistance to $P$. capsici, whereas most of those that did not recognize PcAvr3al were susceptible. Genetic analysis in $N$. repanda, which showed heterogeneity between individuals in its response to PcAvr3a1, indicated that recognition of PcAvr3a1 is mediated by a single dominant gene, reminiscent of $R$ gene-mediated recognition. In addition, we developed a strategy of host-induced gene silencing (HIGS) to investigate the contribution of PcAvr3a1 in nonhost resistance. Using this approach, we show that recognition of PcAvr3a1 is a major contributing factor in nonhost resistance to $P$. capsici in $N$. tabacum. Our results suggest that $R$ gene-mediated recognition of conserved pathogen effectors may be a widespread mechanism of nonhost resistance.

\section{RESULTS}

\section{$N$. tabacum is a nonhost}

\section{for $\boldsymbol{P}$. capsici and responds with a HR.}

To identify novel sources of nonhost resistance to $P$. capsici, we first investigated whether the two model Nicotiana species, $N$. benthamiana and $N$. tabacum, are resistant to P. capsici. $N$. benthamiana was highly susceptible, whereas $N$. tabacum was highly resistant upon inoculation with $P$. capsici by different methods. N. benthamiana leaves infiltrated with a zoospore suspension of $P$. capsici New York isolate B1-3.1 showed a
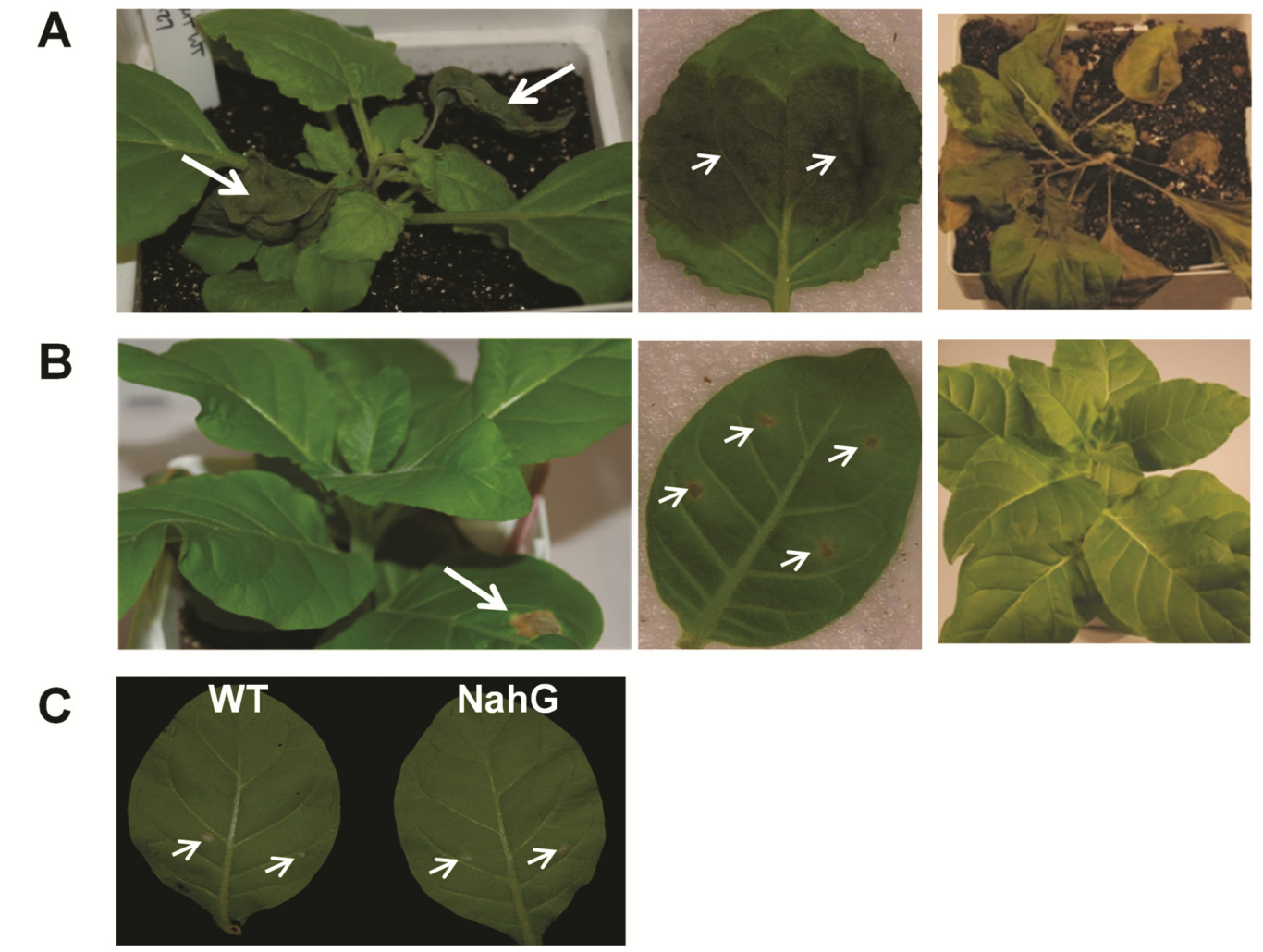

Fig. 1. Resistance to P. capsici in Nicotiana tabacum involves a hypersensitive response. A, N. benthamiana and B, N. tabacum leaves were either infiltrated (left panel) or drop inoculated (center panel) with Phytophthora capsici zoospores. Whole plants were inoculated by applying zoospores to the soil near the main stem (right panel). Representative plants and leaves are shown, presenting typical responses of water-soaked lesions and systemic spread (A) or a hypersensitive response (B). White arrows indicate $P$. capsici zoospore infiltration and inoculation sites at 4 days postinfiltration or inoculation (dpi). C, Wild-type (WT) and NahG transgenic N. tabacum leaves were drop inoculated with P. capsici zoospores and the response was monitored at 4 dpi (white arrows). 
rapid spread of $P$. capsici from the inoculated leaves throughout the plant, resulting in the eventual death of infected areas (Fig. 1A, left panel). However, when a similar inoculation was performed on tobacco leaves (cv. Samsun), the zoospore suspension induced an HR in the inoculation site but no visible growth of $P$. capsici was apparent (Fig. 1B, left panel). Similar results were observed in detached-leaf assays upon inoculation with droplets of $P$. capsici zoospore suspensions; $N$. benthamiana showed infection by $P$. capsici in the inoculated leaves (Fig. 1A, center panel), whereas tobacco responded to $P$. capsici with a HR (Fig. 1B, center panel). Likewise, N. benthamiana plants infected via soil inoculation with $P$. capsici zoospores were susceptible (Fig. 1A, right panel), whereas tobacco plants were resistant (Fig. 1B, right panel). The resistance in tobacco appears to be salicylic acid-independent, as transgenic tobacco plants expressing salicylate hydroxylase (NahG) showed similar resistance when compared with wild type plants and detached leaves from both NahG and wild-type plants developed a HR at the inoculation site (Fig. 1C). Taken together, these results indicate that tobacco is a nonhost for $P$. capsici and suggest that this resistance may be mediated by ETI.

\section{A $P$. capsici Avr3a homolog triggers HR in N. tabacum.}

The $P$. capsici genome has been predicted to encode more than 350 putative RXLR effectors (Lamour et al. 2007, 2011, $2012 \mathrm{~b}$ ). We aimed to determine whether one of these effectors is involved in the induction of HR in tobacco by $P$. capsici. We hypothesized that effector proteins that are recognized by $\mathrm{R}$ proteins in one pathosystem might also be recognized in another. We thus focused on the $P$. capsici RXLR effectors showing similarity to the $P$. infestans Avr3a, as it is one of the few effectors with homologs in the genomes of $P$. capsici, $P$. sojae and $P$. infestans. Furthermore, Avr3a homologs from the latter two species are known to possess avirulence activity in certain cultivars of their host species (Armstrong et al. 2005; Shan et al. 2004). PcAvr3a1 shares $37.7 \%$ and $50.8 \%$ amino acid identity to PiAvr3a and Avr1b proteins of P. infestans and $P$. sojae, respectively (Fig. 2A). We used a collection of 13 Avr3a homologs (Avr3a1 to Avr3a13) cloned from three different isolates of $P$. capsici and one isolate of $P$. tropicalis (Bos 2007). These sequences were cloned into a binary vector without their signal peptide but retaining the RXLR sequence, to allow transient in planta expression via Agrobacterium infiltration (agroinfiltration). When coexpressed with R3a, none of the $P$. capsici Avr3a gene products triggered a HR in $N$. benthamiana (Supplementary Fig. 1). However, we found that one of these homologs (Avr3a1) triggered a HR upon agroinfiltration in tobacco leaves. In addition, Potato virus $X$-mediated expression of Avr3a1 resulted in systemic HR in tobacco plants (Supplementary Fig. 2A). None of the other P. capsici Avr3a homologs, including Avr3a4 and Avr3a11, whose structures have been recently determined (Boutemy et al. 2011; Yaeno et al. 2011), triggered HR in tobacco leaves. To further characterize PcAvr3a1 responses in tobacco and other Nicotiana species, we cloned PcAvr3al from the P. capsici New York isolate B13.1 and used it for all experiments described hereafter. PcAvr3al cloned from $P$. capsici New York isolate B1-3.1 was identical in nucleotide and amino acid sequence to the initial PcAvr3al, which was cloned from $P$. capsici isolates LT263 and LT1534 (Bos 2007), suggesting that PcAvr3al is conserved among different $P$. capsici isolates. In addition, isolate LT1534 triggered a HR in tobacco leaves upon inoculation with zoospores similar to that produced with isolate B1-3.1 (data not shown), suggesting that PcAvr3a1-elicited nonhost resistance is effective against different $P$. capsici isolates carrying PcAvr3al. A BLAST-based search of PcAvr3al against the $P$. capsici genome assembly (v11.0; Joint Genome Institute website) mapped this gene to scaffold 25 . In addition to PcAvr3al, scaffold 25 contained five additional Avr3a-like genes corresponding to $A v r 3 a 3$ (which corresponds to PcAvhl [Dou et al. 2008b]), Avr3a4, Avr3a5, Avr3a11, and a duplicated sequence of $A v r 3 a 12$ of the 13 known Avr3a-like genes (Fig. 2B). These additional Avr3a-like genes shared between 70 and $89 \%$ predicted amino acid identity with PcAvr3a1 but did not elicit a HR in tobacco.

\section{HR induction by PcAvr3a1}

in Nicotiana spp. correlates with resistance to infection.

To expand our analysis of PcAvr3a1-induced responses, we tested a number of Nicotiana accessions covering fourteen different species for their recognition of PcAvr3a1. We used an Agrobacterium-mediated transient expression assay (agroinfiltration) to express PcAvr3a1 in leaf tissues. Infiltration with Agrobacterium species carrying the empty vector served as negative control. We found that at least one accession in nine

A

\begin{tabular}{|c|c|}
\hline PcAvr3a & CNATADSDQNKVV SMVQSL DAR - . - L LNGQADGT RFLRATHENEEEESDRE - ERGLTDLFKT- \\
\hline PsAvr1b & 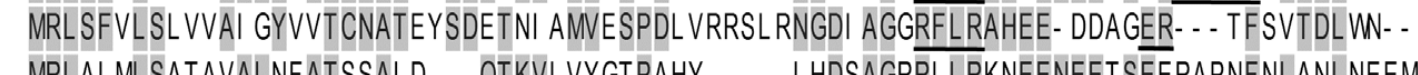 \\
\hline
\end{tabular}

PcAvr3a ....... EKAAVKKKMAKAI MADPSKADDVYOKWADKGYTLTQLSDFLKS ... KTR- GKYDRVYNGYAI HLDY

PsAvr1b ........ KVAAKKLAKAMLADPSKEQKAYEKWAKKGYSLDKI KNWLAI ADPKOK- GKYDRI YNGYTFHLYQS

PiAvr3a FNVAALTERADAKKLAKQL MGNDKLADAAYMMWOHNRVTLDQI DTFLKLASRKT QGAKYNQI YNSYMMHLGLTGY

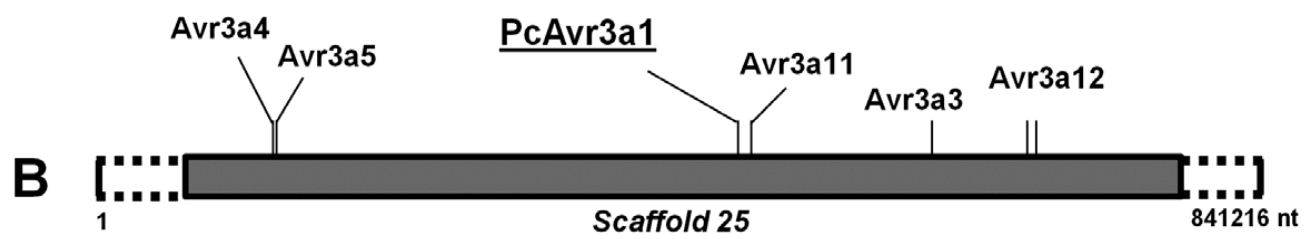

Fig. 2. Multiple alignment of PcAvr3a1 with Phytophthora sojae Avr1b and P. infestans Avr3a. A, Sequences of PcAvr3a1, PsAvr1b, and PiAvr3a were aligned using ClustalW. The predicted signal peptide is indicated by a thin black line above the sequences and the RXLR-EER motif is underlined (bold black). An arrow indicates the start site of the N-terminally truncated version (lacking the signal peptide) of PcAvr3a1 used for transient expression. B, Genomic organization of PcAvr3a1 and other Avr3a-like genes in scaffold 25 of the P. capsici genome assembly v11.0 (Joint Genome Institute database). 
of the fourteen species tested responded to PcAvr3a1 with a HR (Table 1). Interestingly, some accessions of wild-collected $N$. repanda showed PcAvr3a1-induced HR while others did not (Table 1), suggesting that genetic variability in this species may determine different responses to this effector.

The elicitation of an HR by a given effector is typically associated with $R$ gene-mediated resistance. Consistent with this, PcAvr3a1 induced a HR in N. tabacum similar to the response produced by the infiltration of $P$. capsici zoospores, whereas in the susceptible $N$. benthamiana, PcAvr3a1 did not produce any visible HR (Fig. 3A). Likewise, we tested the resistance to $P$. capsici in the same Nicotiana species as tested for PcAvr3a1-mediated HR. Detached leaves were inoculated with a zoospore suspension of the P. capsici isolate B1-3.1 and disease symptoms were monitored. The Nicotiana species that showed the highest susceptibility to $P$. capsici were $N$. benthamiana, $N$. rustica, $N$. clevelandii, and $N$. otophora, as evidenced by spreading water-soaked lesions (Fig. 3B and C). No visible HR was induced by PcAvr3a in $N$. benthamiana or $N$. rustica and only weak or very weak necrosis was observed in $N$. otophora and $N$. clevelandii, respectively, upon agroinfiltration of PcAvr3a1 (Table 1; Fig. 3B, insets). N. tabacum, N. sylvestris, $N$. glutinosa, $N$. edwardsonii, and $N$. undulata, which respond with a strong HR upon agroinfiltration of PcAvr3a1 (Table 1; Fig. 3B, insets), did not permit spreading of $P$. capsici, instead showing an HR-like response at the sites of inoculation (Table 1; Fig. 3B and C). The correlation between PcAvr3a1-elicited HR and resistance to P. capsici suggests that these nonhost species may possess one or more endogenous $R$ genes whose product recognizes PcAvr3a1 and confers resistance to $P$. capsici. Interestingly, however, $N$. plumbaginifolia and some $N$. repanda accessions did not show PcAvr3a1associated HR but were still resistant to P. capsici (Table 1; Fig. 3B), suggesting that these species may possess additional mechanisms of resistance to $P$. capsici.

\section{PcAvr3a1 is recognized}

by a single dominant gene product in $N$. repanda.

Since PcAvr3a1-triggered HR in Nicotiana species suggested recognition by an endogenous $\mathrm{R}$ protein, we explored the inheritance of this recognition in a cross between $N$. repanda individuals from pop. 15 (no HR) and pop. 18 (HR). As most plant $R$ genes are dominant, we expected that recognition of PcAvr3a1 would be dominant in the $F_{1}$ progeny and segregate in a 3:1 ratio in the $\mathrm{F}_{2}$ progeny. Indeed, in the $\mathrm{F}_{1}$ generation, all eight plants tested showed an HR when agroinfiltrated with PcAvr3a1 (Supplementary Table 1). Furthermore, a pattern of segregation for PcAvr3a1 recognition in $\mathrm{F}_{2}$ plants that fits the expected 3:1 ratio (31 plants showing HR versus 13 plants showing no HR) was observed $\left(\chi^{2}=0.48\right.$ and $\left.P>0.45\right)$, suggesting that a single dominant $R$ gene is responsible for recognition of PcAvr3a1 in $N$. repanda. Similar results were obtained with the $\mathrm{F}_{2}$ progeny of the cross $N$. repanda pop. 15 (no HR) $\times$ pop. 16 (HR) (data not shown). From these data, we conclude that recognition of PcAvr3a1 in Nicotiana spp. is inherited as a single dominant character, consistent with it being conferred by a canonical $R$ gene.

\section{A major contribution of PcAvr3a1}

\section{in nonhost resistance against $P$. capsici revealed by HIGS.}

To confirm the contribution of PcAvr3al to nonhost resistance, we developed a strategy to silence PcAvr3al by HIGS. This plant-mediated RNA interference (RNAi) approach, in which a double-stranded (ds)RNA of the target gene is expressed in plant tissue to silence a gene of an organism that feeds on that plant, has been first successfully applied to plantinsect and plant-nematode interactions (Baum et al. 2007;
Huang et al. 2006; Mao et al. 2007). HIGS has been recently implemented in the fungal plant pathogens Blumeria graminis (Nowara et al. 2010), Puccinia striiformis f. sp. tritici (Yin et al. 2011), Fusarium verticillioides (Tinoco et al. 2010), and Puccinia triticina (Panwar et al. 2013). However, HIGS has not been reported for an oomycete. Therefore, we explored the possibility that silencing of PcAvr3a1 might take place in $P$. capsici growing on plant tissue expressing a dsRNA of PcAvr3al.

We constructed an expression vector to express a 369-nucleotide fragment of PcAvr3al as an inverted repeat, capable of forming an RNA hairpin when expressed in planta (hpAvr3a1). Tobacco leaves were agroinfiltrated either with hpAvr3a1 or with the empty vector pART27. The P0 protein of Beet Western yellows virus is a suppressor of posttranscriptional gene silencing (Pfeffer et al. 2002) that targets Argonaute (AGO) proteins for degradation and, as such, allows for sustained transient expression and accumulation of the dsRNA construct and derived small interfering RNAs (Baumberger et al. 2007; Bortolamiol et al. 2007; Csorba et al. 2010). We, thus, coexpressed the P0 protein in this assay, as we reasoned that it would increase the amount of PcAvr3al-derived dsRNA in the plant. After agroinfiltration, leaves were detached, were challenged with a zoospore suspension of $P$. capsici, and were placed on wetted filter paper in a sealed plastic bag. Lesion sizes at the inoculation sites were then measured 2, 3, and 4 days after inoculation. Under these conditions, we observed that infection with $P$. capsici could be established at a small

Table 1. Analysis of hypersensitive reaction (HR) induction by PcAvr3a1 and nonhost resistance to Phytophthora capsici in Nicotiana species or accessions

\begin{tabular}{|c|c|c|c|}
\hline Species/accession & pBin61 & PcAvr3a1 ${ }^{a}$ & P. capsici infection ${ }^{b}$ \\
\hline N. benthamiana & - & - & $\mathrm{S}$ \\
\hline N. tabacum 'Samsun' & - & +++ & $\mathrm{R}$ \\
\hline N. tabacum 'Xanthi' & - & +++ & $\mathrm{R}$ \\
\hline N. tabacum 'W38' & - & +++ & $\mathrm{R}$ \\
\hline $\begin{array}{l}\text { N. tabacum 'Virginia } \\
\text { goldleaf' }\end{array}$ & - & +++ & $\mathrm{R}$ \\
\hline N. clevelandii & - & $-1+$ & $\mathrm{S}$ \\
\hline N. edwardsonii & - & +++ & $\mathrm{R}$ \\
\hline N. rustica & - & - & $\mathrm{S}$ \\
\hline N. repanda pop. 14 & - & +++ & $\mathrm{R}$ \\
\hline N. repanda pop. 15 & - & - & $\mathrm{R}$ \\
\hline N. repanda pop. 16 & - & ++ & $\mathrm{R}$ \\
\hline N. repanda pop. 10 & - & + & $\mathrm{R}$ \\
\hline N. repanda pop. 17 & - & + & nd \\
\hline N. repanda pop. 18 & - & +++ & $\mathrm{R}$ \\
\hline N. glutinosa & - & +++ & $\mathrm{R}$ \\
\hline N. glutinosa TW58 & - & +++ & nd \\
\hline N. glutinosa TW59 & - & +++ & nd \\
\hline N. glutinosa TW61 & - & +++ & nd \\
\hline N. glutinosa TW63 & - & +++ & $\mathrm{R}$ \\
\hline N. glutinosa TW64 & - & +++ & nd \\
\hline N. glutinosa TW65 & - & +++ & nd \\
\hline N. glutinosa TW66 & - & ++ & $\mathrm{R}$ \\
\hline N. sylvestris (50578) & - & +++ & $\mathrm{R}$ \\
\hline N. sylvestris TW136 & - & +++ & $\mathrm{R}$ \\
\hline N. langdorfii & - & +++ & nd \\
\hline N. undulata & - & +++ & $\mathrm{R}$ \\
\hline N. macrophylla & - & +++ & nd \\
\hline N. plumbaginifolia & - & - & $\mathrm{R}$ \\
\hline N. otophora TW94 & - & + & $\mathrm{S}$ \\
\hline N. otophora TW95 & - & +++ & nd \\
\hline N. otophora TW96 & - & ++ & $\mathrm{S}$ \\
\hline N. otophora TW97 & - & $-/+$ & $\mathrm{S}$ \\
\hline
\end{tabular}

${ }^{a}$ Scale of intensity of HR at 5 days postinoculation (dpi): $-=$ no HR; + = weak $\mathrm{HR} ;++=$ moderate $\mathrm{HR} ;+++=$ strong $\mathrm{HR} ;-/+=$ very weak and inconsistent HR.

${ }^{\mathrm{b}}$ In detached leaves inoculated with droplets containing $4 \times 10^{3} \mathrm{P}$. capsici zoospores. $\mathrm{S}=$ susceptible; $\mathrm{R}=$ resistant; $\mathrm{nd}=$ not determined. 
percentage of inoculation sites in nonagroinfiltrated tobacco leaves, although this is likely a consequence of a high concentration of inoculum and high humidity. Nonetheless, $P$. capsici was able to spread on leaves expressing hpAvr3a1 more frequently and to a greater extent than on vector-infiltrated leaves (Figs. 4A and B; Supplementary Fig. S3) while infection of the latter with $P$. capsici typically produced an HR at the inoculation site.

We used $N$. benthamiana as a control for the RNAi assays, as PcAvr3a1 does not produce a visible HR in N. benthamiana upon agroinfiltration and this species is susceptible to $P$. capsici (Table 1; Figs. 1B and 3). Figures 4A and B show spreading of $P$. capsici from the inoculation site at a similar rate in both hpAvr3a1- and pART27-infiltrated $N$. benthamiana leaves. This suggests that hpAvr3a1 did not significantly affect $P$. capsici virulence and that the ability of $P$. capsici to spread on tobacco leaves expressing hpAvr3a1 is likely due to a loss of avirulence. Even though no difference in infection was observed in $N$. benthamiana leaves infiltrated with either hpAvr3a1 or pART27, we expected that silencing of PcAvr3al by growing $P$. capsici in $N$. benthamiana leaves expressing hpAvr3a1 would still compromise avirulence to tobacco. To verify this, we inoculated tobacco leaves with leaf discs of $P$. capsici growing on $N$. benthamiana leaves infiltrated with either hpAvr3a1 or empty vector. We found that infection of
$P$. capsici in tobacco is enhanced when the pathogen has been previously grown on $N$. benthamiana leaves infiltrated with hpAvr3a1 (Supplementary Fig. 4), suggesting that PcAvr3a1 expression was down-regulated in $P$. capsici growing in $N$. benthamiana and, consequently, did not induce a resistance response in tobacco leaves.

Downregulation of PcAvr3al transcripts in $P$. capsici growing on hpAvr3a1-agroinfiltrated $N$. benthamiana tissue was confirmed by semiquantitative reverse transcription-polymerase chain reaction (RT-PCR). A fragment of the PcAvr3al transcript was amplified from total cDNA, using specific primers designed to anneal outside of the hairpin sequence. Figure $4 \mathrm{C}$ and D shows that PcAvr3al expression was significantly reduced in $P$. capsici growing on $N$. benthamiana leaves infiltrated with hpAvr3a1, as compared with the empty vector. In contrast, amplification of the $P$. capsici Act-A gene was unaffected by the hairpin (Fig. 4C and D). No amplification was observed in a control PCR using total RNA without a prior RT reaction as template (data not shown). These experiments were performed on $N$. benthamiana, as $P$. capsici did not grow on non-hairpin expressing $N$. tabacum leaves. However, our results are consistent with a similar action of the hpAvr3a1 construct in the latter plant. Together, these results suggest that downregulation of PcAvr3a1 allows P. capsici to grow on the nonhost (tobacco), indicating that recognition of
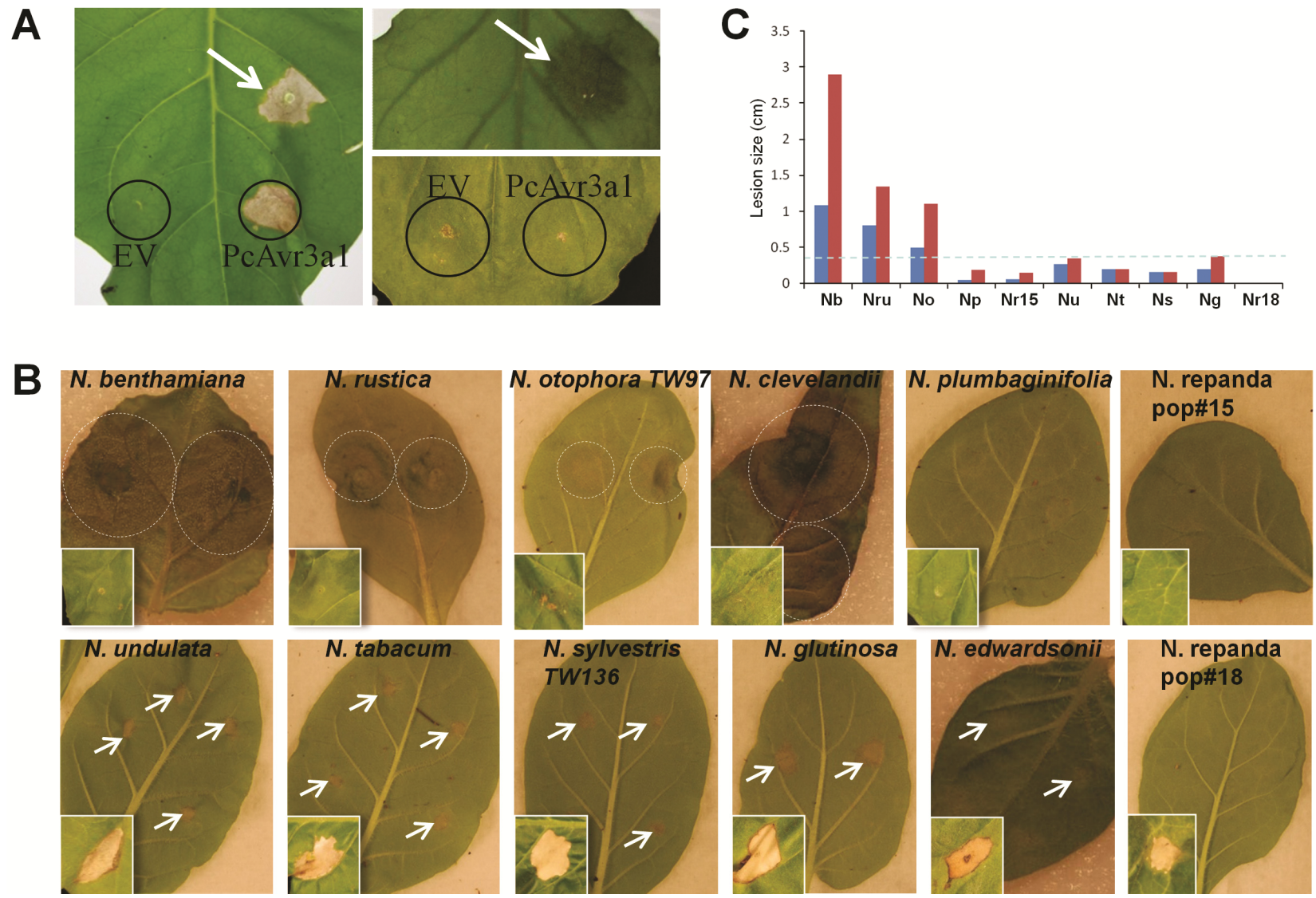

Fig. 3. Recognition of PcAvr3a1 correlates with resistance to Phytophthora capsici in multiple Nicotiana species. A, N. tabacum (left panels) and N. benthamiana (right panels) leaves were infiltrated either with $P$. capsici zoospores (white arrows) or agroinfiltrated (black circles) with either pBin61 (EV) or pBin61-Avr3a1 (PcAvr3a1). B, Detached leaves of diverse Nicotiana species were inoculated with droplets containing $4 \times 10^{3}$ zoospores of $P$. capsici or agroinfiltrated with pBin61-PcAvr3a1 (inset pictures). Disease symptoms consisting of expanding water-soaked lesions are shown on the leaves of Nicotiana species in which PcAvr3a does not trigger a hypersensitive response (HR) (top panels, white dashed circles), except in $N$. plumbaginifolia. In Nicotiana species in which PcAvr3a1 triggers a HR (B, bottom panels), a HR reaction is shown at the inoculation sites (white arrows). Photographs were taken at 5 days postinoculation (dpi), except for the $N$. benthamiana leaf showing infection by $P$. capsici (A, upper left panel), which was photographed at 2 dpi. C,. Lesion size on detached leaves of Nicotiana species inoculated with P. capsici zoospores. Blue and red bars show the lesion size in centimeters at 2 and 3 dpi, respectively. The dotted line indicates the size of the inoculation drop containing $P$. capsici zoospores. Nb, N. benthamiana; Nru, $N$. rustica; No, $N$. otophora; $\mathrm{Np}, N$. plumbaginifolia; Nr15, N. repanda pop. $15 ; \mathrm{Nu}, N$. undulata; Nt, N. tabacum; Ns, N. sylvestris; Ng, N. glutinosa; and Nr18, N, repanda pop.18. 
PcAvr3a1 plays a major role in nonhost resistance to $P$. capsici.

\section{DISCUSSION}

Despite the relatively wide host range of $P$. capsici, there are few sources of major gene resistance to $P$. capsici in host species and, consequently, limited opportunity for the introduction of resistance via traditional breeding methods. As such, we have investigated mechanisms of resistance to $P$. capsici in nonhost plants. Consistent with a previous report (Hartman and Huang 1993), we failed to infect several cultivars of tobacco by soil or foliar inoculation of $P$. capsici zoospores (Table 1; Figs. 1 and 3). In addition to isolates B1-3.1 and LT1534, other $P$. capsici isolates (New York isolates 0664-1, 06120-1, A3-3.1, 0752-2, 0759-8, and 8.2-1) also failed to infect tobacco plants or leaves (data not shown). Together with a lack of report of $P$. capsici infecting tobacco in the field, this indicates that $N$. tabacum is not a natural host for this pathogen. We hypothesized that this nonhost resistance may be simi- lar to $R$ gene-mediated resistance. $R$ genes are traditionally identified by virtue of their presence in some but not all cultivars, allowing for their definition by genetics. We reasoned that, in some cases, effective and possibly broad spectrum $R$ genes might be found in nonhosts but may not be genetically apparent due to a lack of heterogeneity. If so, then it would be predicted that such an $R$ gene would recognize a specific Avr protein from the pathogen and that this recognition would be sufficient to induce an HR response typical of R/Avr protein interactions.

In theory, any putative effector protein could have the potential to be recognized by a plant $R$ gene. However, for durable, broad-spectrum resistance characteristic of nonhost resistance, it would be expected that an effective $\mathrm{R}$ protein would recognize an effector with essential and conserved function. With the sequencing of several oomycete pathogen genomes, hundreds of candidate RXLR effectors have been identified (Baxter et al. 2010; Haas et al. 2009; Lamour et al. 2007, 2012b; Tyler et al. 2006; Win et al. 2007), and several of these have been found to function as Avr proteins in P. sojae (Avr1b, Avrla,
A
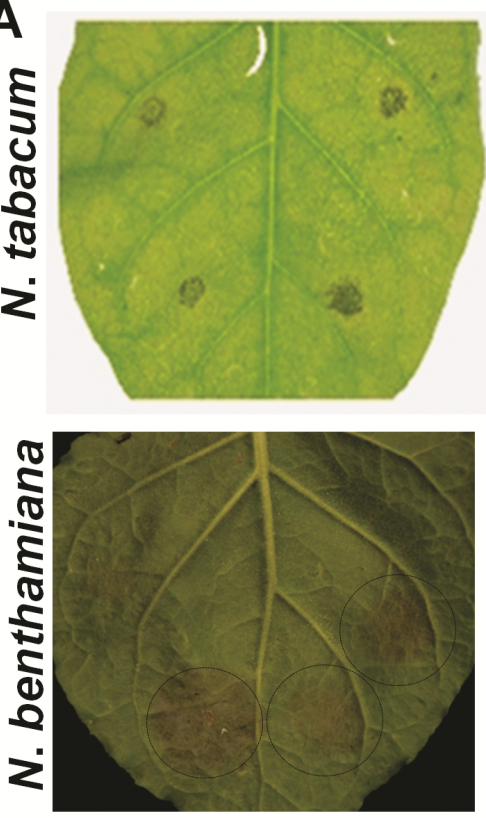

EV
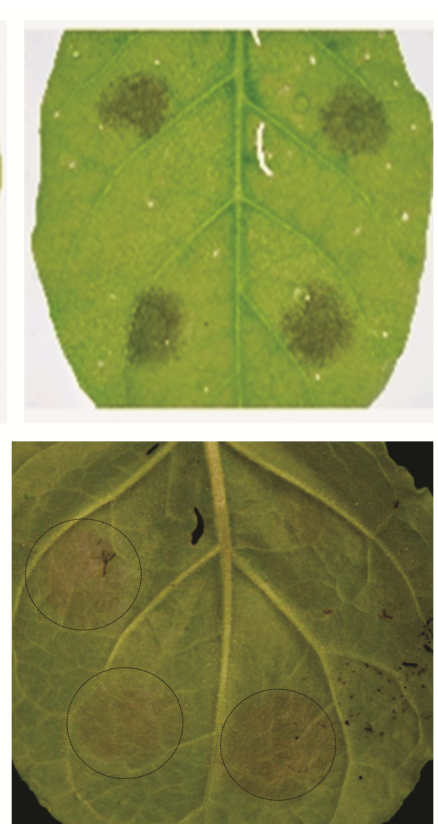

hpAvr3a1
B
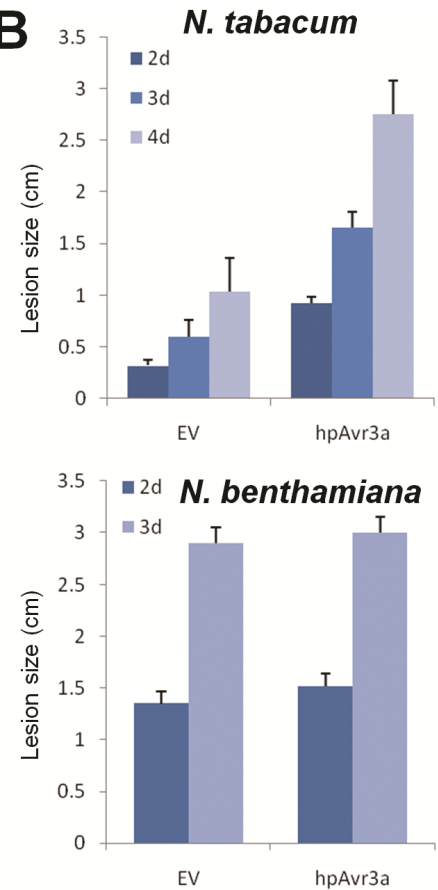
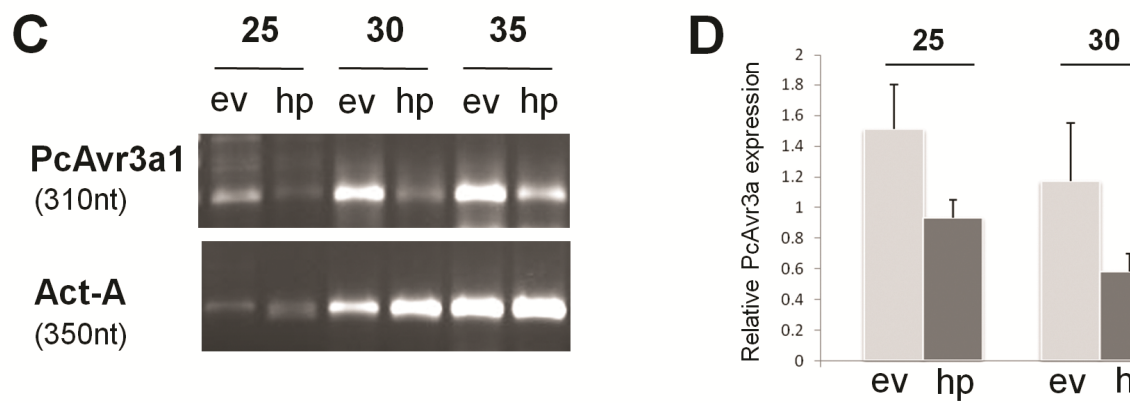

35

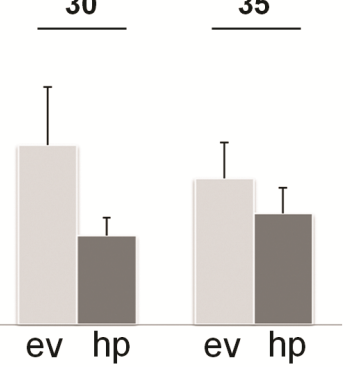

Fig. 4. Host-induced gene silencing of PcAvr3al increases infection of Phytophthora capsici in resistant tobacco leaves. A, Nicotiana tabacum (upper panel) and $N$. benthamiana (bottom panel) leaves were agroinfiltrated with a hairpin construct of PcAvr3a1 (right panel; hpAvr3a1) or with the empty vector (EV; left panel) as control. Subsequently, the agroinfiltrated areas of the leaves were inoculated with a zoospore suspension of $P$. capsici and the infection was monitored at 2, 3, and 4 days postinoculation (dpi). Shown are the results from a representative experiment from at least three independent biological replicates. B, Infection was quantified by measuring the lesion sizes in tobacco (upper graph) and $N$. benthamiana (bottom graph) from three independent experiments. Circles on $N$. benthamiana leaves show $P$. capsici-infected areas. Error bars represent standard error. C, mRNA was isolated from $P$. capsici grown on $N$. benthamiana leaves infiltrated with hpAvr3a1 (hp) or with empty vector (EV). Reverse transcription-polymerase chain reaction (PCR) was performed using primers targeting PcAvr3al (upper panel) or the $P$. capsici Act-A gene (lower panel). Relative quantification of $P c A v r 3 a 1$ transcript values normalized to Act-A expression levels are shown in B after 25, 30, and 35 PCR cycles. This is a representative experiment from three independent biological replicates with similar results. Error bars in D represent standard error. 
Avr1k, Avr3a/5, Avr3b, Avr3c, and Avr4/6) (Dong et al. 2009, 2011a and b; Dou et al. 2010; Qutob et al. 2009; Shan et al. 2004; Song et al. 2013), P. infestans (Avr3a, Avr4, Avr-blb1, Avr-blb2, Avr2) (Armstrong et al. 2005; Gilroy et al. 2011; Oh et al. 2009; van Poppel et al. 2008; Vleeshouwers et al. 2008), and Hyaloperonospora arabidopsidis (ATR1 and ATR13) (Allen et al. 2004; Rehmany et al. 2005). Interestingly, among these Avr effectors, two appear to show homology, Avr1b of $P$. sojae and Avr3a of $P$. infestans. These proteins, in turn, show homology to PcAvr3a1 (Fig. 2), which we show to possess Avr activity, as defined by the ability to induce a HR, on multiple Nicotiana species (Fig. 3; Table 1). This suggests that members of this protein family may have either structural or functional properties that make them inherently predisposed to recognition by plant $\mathrm{R}$ proteins. What these properties might be is unclear at present. Indeed, a survey of bacterial effectors showed that homologs of known Avr proteins are very likely to be recognized in several plant species, and in general, effectors from nonhost pathogens induced HR more commonly on nonhost plants (Wroblewski et al. 2009). Our demonstration that PcAvr3a1 also has the potential to be recognized by plant $\mathrm{R}$ proteins would appear to validate our hypothesis that, if a protein has avirulence function in one context, then homologous proteins may be highly likely to be recognized in another plant-pathogen interaction. We suggest that this principle may be broadly extendable to other systems in the search for sources of resistance.

The induction of a strong HR by PcAvr3al correlates with resistance to $P$. capsici (Fig. 3B; Table 1). These results are consistent with the hypothesis that an endogenous $\mathrm{R}$ protein recognizes PcAvr3al in those species in which a HR is produced and that this response is sufficient for restricting $P$. capsici infection. This is further supported by genetic analysis in $N$. repanda, which shows that recognition is determined by a single dominant gene, as is normally seen with plant $R$ genes. At the same time, it is possible that other effectors from $P$. capsici might also be involved in nonhost resistance in Nicotiana species. For example, the observation that N. plumbaginifolia and some $N$. repanda accessions do not recognize PcAvr3a1 yet are still resistant to $P$. capsici suggests that either other $R$ genes or other defense mechanisms are being activated in these species. The varying levels of resistance against $P$. capsici that we found in the different Nicotiana species, in addition to other potential mechanisms of resistance as observed in $N$. plumbaginifolia and some $N$. repanda accessions, lead us to propose the Nicotiana genus as a model system to study $P$. capsici-plant interactions and mechanisms of resistance.

Demonstration that PcAvr3a1 is a major factor in inducing plant defenses requires the ability to determine infection outcome of the pathogen in the absence of this effector protein. Since genetic knock-out strategies have not been developed for this pathogen, we opted to alter PcAvr3al gene expression, using an RNAi strategy. RNAi-mediated gene silencing by application of dsRNA to protoplasts has been reported to occur in P. infestans (Judelson and Tani 2007; van West et al. 1999; Whisson et al. 2005). In addition, Dicer-like, AGO, and histone deacetylase genes, fundamental components of the RNAi pathway, have been identified in $P$. infestans (Vetukuri et al. 2011). Furthermore, the use of plant-mediated RNAi (HIGS) as a tool for fungal reverse genetics has been recently implemented in several fungal plant pathogens (Nunes and Dean 2012), e.g., Blumeria graminis (Nowara et al.) and in the wheat stripe rust fungus Puccinia striiformis f. sp. tritici (Yin et al. 2011). In both cases, the fungus grows biotrophically in the host plant and forms haustorial cells. HIGS has also been reported in another fungal pathogen, Fusarium verticillioides (Tinoco et al. 2010), and in the plant parasitic weed
Tryphysaria spp. (Tomilov et al. 2008). We developed a HIGS approach to silence PcAvr3al by growing $P$. capsici on plant tissue transiently expressing a hairpin construct of the gene. Although RT-PCR showed that only partial gene silencing of PcAvr3a1 expression was achieved using this approach, this silencing was clearly sufficient to reveal a phenotype in that it allowed $P$. capsici zoospores to colonize tobacco leaves (Fig. 4). Silencing of other Avr3a-like genes in the $P$. capsici strain used in this work is possible. However, no effects on infection by $P$. capsici in $N$. benthamiana were observed in the leaves expressing the HIGS construct. Furthermore, PcAvr3a1 was the only Avr3a-like from $P$. capsici that produced a HR response in tobacco leaves and is, thus, likely to be the only Avr3a homolog involved in inducing resistance. Gene downregulation by HIGS may not be complete due to the transient nature of these experiments or because RNAi leads to a varying reduction of the transcript levels. However, complete silencing of target $P$. capsici genes may not be necessary to demonstrate avirulence function, using this technique. Even if only a small percentage of individual $P$. capsici zoospores or mycelia are efficiently silenced, these will be strongly selected for on resistant tobacco leaves. Furthermore, we have found that inoculation of tobacco leaves with $P$. capsici mycelium plugs frequently allows the pathogen to proliferate (data not shown). This suggests that very high infection titers of pathogen overwhelm initial resistance responses and that, once an infection is established, nonhost resistance mechanisms in tobacco are no longer effective. This may be due to a switch to a necrotrophic phase by the pathogen, which would no longer be controlled by $R$ gene responses. As such, silencing of a potential Avr gene would be essential to establishing infection, but the maintenance of silencing may be less important. Thus, HIGS may be very useful for investigating avirulence functions of $P$. capsici effectors due to the positive selection for avirulent individuals. At the same time, this technique may not be as effective in studying virulence function on susceptible plants as the opposite principle would be expected, that is, the selection of poorly silenced, more virulent individuals. Further study will be required to investigate the general applicability of this technique to the study of $P$. capsici biology and its application to other oomycetes. Nonetheless, this technique has allowed us to demonstrate the main point of this report, i.e., that PcAvr3a1 is a major elicitor of nonhost resistance to $P$. capsici in tobacco, further supporting our conclusion that this nonhost resistance is, in fact, mediated by one or more endogenous $R$ genes.

The nature of the one or more $R$ proteins mediating recognition of PcAvr3a1 is presently unclear. The fact that it is recognized upon expression inside the plant cell and the dominant nature of the $N$. repanda $R$ gene would suggest that it is a canonical member of the NB-LRR class of proteins. It is interesting to note that PcAvr3a1 is recognized in multiple Nicotiana species. $R$ genes are highly variable and orthologous genes from different species often have very different recognition specificities (Grube et al. 2000; Mazourek et al. 2009) and the same Avr protein can be recognized by entirely different $\mathrm{R}$ proteins of different plant species (Ashfield et al. 2004). However, it is not unusual for highly similar R proteins from species within the same plant family to have similar recognition specificities, such as the Prf proteins of tomato and N. benthamiana (Peart et al. 2002), the $\mathrm{Rx}$ and $\mathrm{Rx} 2$ proteins of Solanum tuberosum subsp. andigena and Solanum acaule, respectively (Bendahmane et al. 1999, 2000), as well as the $N^{\prime}$ gene of tobacco and the $L$ genes of pepper (Sekine et al. 2012; Tomita et al. 2011). Thus, given the relatedness of these species, we suggest that the recognition of PcAvr3al is likely to be mediated by paralogous $\mathrm{R}$ proteins whose function and recognition 
specificity has been retained in multiple Nicotiana species. The reasons for this conservation are not yet clear. The presumed recent spread of $P$. capsici would suggest that this pathogen has not played a selective role in maintenance of PcAvr3a1 recognition in the disparate habitats of these different species. However, other pathogens, including other Phytophthora species, encoding effectors with similar structure or function may have played selective roles. At the same time, recognition of PcAvr3a1 may have been important in defense against a specific pathogen only in the past and a lack of selection may explain the loss of recognition in several species and even in different accessions of the same species (Table 1).

Both the guard hypothesis and the decoy hypothesis suggest that pathogen effector proteins are detected by virtue of their interactions with host recognition cofactors that are either virulence targets or that look like virulence targets (Collier and Moffett 2009; Dangl and Jones 2001; van der Hoorn and Kamoun 2008). Given that there are likely a limited number of such cofactors, it is perhaps not surprising that many effectors are recognized in plants despite a lack of evolutionary history between pathogen and host. As such, susceptibility (or lack of recognition) may, indeed, be the exception for most plantpathogen interactions. We predict that recognition of a given effector protein may be relatively common in nonhost plants and that nonhost plants may be a rich source of effective and durable $R$ genes.

In conclusion, we have shown that tobacco and other Nicotiana species are nonhosts for $P$. capsici and respond to $P$. capsici infection with a HR. Our results indicated that PcAvr3a1, a putative RXLR effector protein from $P$. capsici, elicits nonhost resistance in tobacco by triggering a HR, most likely by activating an NB-LRR protein. Furthermore, we show that HIGS may be a powerful tool for demonstrating avirulence activity of $P$. capsici effector proteins.

\section{MATERIALS AND METHODS}

\section{Plant and $P$. capsici material.}

All plants were grown from lab seed stocks or from seed stocks obtained from the United States Department of Agriculture germplasm resources information network, with the exception of $N$. repanda. $N$. repanda seeds were collected from the wild in California and were obtained from R. Harris (Cornell University, Ithaca, NY, U.S.A.). Seeds were collected from individual plants from different populations (pop. \#) and were used to test for resistance and recognition of PcAvr3a. All plants were grown in greenhouses with a 16-h light and 8-h dark cycle at $22^{\circ} \mathrm{C}$.

P. capsici isolates B1-3.1, 0664-1, 06120-1, A3-3.1, 0752-2, 0759-8, and 8.2-1 were obtained from C. Smart (Cornell University). Isolate LT1534 was obtained from K. Lamour (University of Tennessee, Knoxville, TN, U.S.A.). All of these (except LT1534) are field isolates collected in the state of New York. Isolates were maintained in the dark at $26^{\circ} \mathrm{C}$ on plates containing $20 \%$ V8 vegetable juice agar complemented with $1 \mathrm{~g}$ of $\mathrm{CaCO}_{3}$ per liter.

\section{P. capsici Avr3a-like sequences.}

P. capsici Avr $3 a$-like sequences (Avr3a1 to Avr3a13) were amplified from three different isolates of $P$. capsici and one isolate of $P$. tropicalis, as previously described (Bos 2007). All 13 Avr3a clones were subcloned into the binary vector pBin61 for transient expression under the Cauliflower mosaic virus $35 \mathrm{~S}$ promoter in plant leaves. The sequence of the Avr3a clone (Avr3a1) that induced a HR in tobacco was chosen to amplify the Avr3a gene from the P. capsici New York isolate B1-3.1 (provided by C. Smart, Cornell University, Geneva, NY,
U.S.A.) used in this study (PcAvr3al). The PcAvr3al open reading frame, excluding the predicted signal peptide coding sequence and including part of the $3^{\prime}$ untranslated region was amplified from genomic DNA of $P$. capsici B1-3.1 using primers PcAvr3a1-for 5'-GGATCTAGATGGTGCAGTCGCT CGATGCGCG-3' and PcAvr3a1-rev 5'-GGACCCGGGCGA GTTGTCATTGACGTTACTC-3'. After digestion with XbaI and $S m a \mathrm{I}$ the PCR products were ligated into the same sites of pBin61, resulting in the plasmid pBin61-PcAvr3al that was introduced in Agrobacterium tumefaciens C58C1 for agroinfiltration assays.

\section{Construction of a PcAvr3al hairpin.}

A hairpin construct of $P c A v r 3 a l$ was generated by inserting the PcAvr $3 a$ coding sequence in sense and antisense orientation into pHannibal (Wesley et al. 2001) as follows. For inserting into the Ai site of pHannibal, PcAvr3al was amplified from $P$. capsici B1-3.1 DNA using primers Ai-PcAvr3a1-for 5'-GGAGAATTCGGTGCAGTCGCTCGATGCGCG-3' and Ai-Avr3a-rev 5'-GGAGGTACCCGAGTTGTCATTGACGTT ACTC-3'. PCR products were digested with EcoRI and KpnI and were inserted into the same sites of pHannibal. Primers Bi-PcAvr3a-for 5'-GGATCTAGAGGTGCAGTCGCTCGATG CGCG-3' and Bi-Avr3a-rev 5'-GGAATCGATCGAGTTGTCA TTGACGTTACTC-3' were used to amplify PcAvr3a1, followed by subcloning into the $\mathrm{XbaI}$ and $\mathrm{ClaI}$ sites within the $\mathrm{Bi}$ site of pHannibal. The hairpin cassette was released with NotI and was transferred into the same site of the binary vector pART27 (Gleave 1992), generating plasmid pART-hpAvr3a1. All constructs were verified by sequencing.

\section{Agroinfiltration and $P$. capsici inoculation.}

For agroinfiltration of PcAvr3a1 in Nicotiana species, Agrobacterium carrying pBin61-PcAvr3a1 was grown in Luria Bertani medium, containing kanamycin at the rate of $50 \mu \mathrm{g} / \mathrm{ml}$ and tetracycline at $5 \mu \mathrm{g} / \mathrm{ml}$, at $28^{\circ} \mathrm{C}$ overnight. The bacteria were pelleted by centrifugation (15 min at 4,000 rpm) and were resuspended in induction buffer containing $1 \mathrm{mM} \mathrm{MgCl}_{2}$, $10 \mathrm{mM}$ morpholineethanesulfonic acid, $\mathrm{pH} 5.6$, and $200 \mu \mathrm{M}$ acetosyringone to an optical density at $600 \mathrm{~nm}\left(\mathrm{OD}_{600}\right)=0.3$. Agrobacterium tumefaciens carrying the empty pBin61 vector served as control. Agroinfiltration was performed on the abaxial side of the leaf with a needleless syringe. Plants were kept in the greenhouse after infiltration and HR was monitored for 5 days.

For HIGS, N. tabacum and N. benthamiana leaves from 3to 4-week-old plants were infiltrated with Agrobacterium tumefaciens carrying pART-hpAvr3a1 at an $\mathrm{OD}_{600}=0.6$ in induction buffer, along with Agrobacterium tumefaciens carrying $\mathrm{P} 0$ at an $\mathrm{OD}_{600}=0.6$ in a $2: 1$ volume ratio. A mixture of cultures of Agrobacterium tumefaciens carrying pART27 plus Agrobacterium tumefaciens carrying P0 was used as control. The 2:1 ratio of the Agrobacterium cultures carrying hpAvr3a1 and P0 was determined by analyzing the silencing output of PcAvr3al by the hpAvr3a1 construct in the presence of $\mathrm{P} 0$ in planta. After agroinfiltration, at 3 to 5 days, leaves were detached and inoculated with a zoospore suspension of $P$. capsici isolate B1-3.1 and were incubated in a humid chamber at $26^{\circ} \mathrm{C}$. A $20-\mu \mathrm{l}$ drop containing 10,000 zoospores was used for $N$. tabacum and 500 zoospores for $N$. benthamiana.

For zoospore production, P. capsici was grown on $20 \% \mathrm{~V} 8$ vegetable juice agar complemented with $1 \mathrm{~g}$ of $\mathrm{CaCO}_{3}$ per liter for 3 to 5 days in the dark at $26^{\circ} \mathrm{C}$. Sporulation was induced by growing for three additional days under continuous fluorescent light. Release of zoospores was induced by flooding the cultures with sterile deionized water and incubation at $6^{\circ} \mathrm{C}$ for 30 to $60 \mathrm{~min}$ and, then, at room temperature for $1 \mathrm{~h}$. The amount 
of zoospores in the solution was determined by vortexing an aliquot of the zoospore solution for $30 \mathrm{~s}$ to induce encystment and counting the number of cysts with a hemacytometer. For inoculation of Nicotiana species, detached leaves were inoculated with $10-\mu l$ drops containing 4,000 zoospores and were kept in a humid chamber at $26^{\circ} \mathrm{C}$. Leaves attached to the plant were infiltrated in the abaxial side, using a needleless syringe with $25 \mu \mathrm{l}$ of zoospore solution (4,000 zoospores) and the plants were kept at $26^{\circ} \mathrm{C}$.

\section{RT-PCR.}

Total RNA was extracted from N. benthamiana and N. tabacum tissue agroinfiltrated with pART-hpAvr3a and inoculated with $P$. capsici using an RNeasy mini kit (Qiagen, Valencia, CA, U.S.A.), followed by digestion with RNase-free DNase I. cDNA was synthesized from $2 \mu \mathrm{g}$ of total RNA by oligo(dT)primed RT using Superscript III (Invitrogen, Carlsbad, CA, U.S.A.). PcAvr3al-specific primers that aligned outside of the hairpin sequence (Avr3a_5'_for: 5'-CCGACCAAAACAAGAT GTCGATG-3' and Avr3a_stop_rev: 5'-CCAGGTGGATCGCG TACCCGTTG-3') were used to amplify the transcripts of this gene from $P$. capsici-infected tissue. Using BLAST under low-stringent analysis conditions (90\% identity) and in silico PCR analysis with the pDRAW32 program, we found that the reverse primer aligned only and specifically to the region corresponding to PcAvr3al in scaffold 25, whereas the forward primer aligned to the same region of PcAvr3al as well as three other regions in same scaffold that are 32,010 (PcAvr3a3), 53,201 (PcAvr3a12), and 82,850 nt away from the reverse primer. Thus, the pair of primers used for RT-PCR should only amplify a fragment corresponding to PcAvr3al under the PCR conditions used in this work. Expression of the $P$. capsici Actin- $A$ gene (amplified by primers $5^{\prime}$-CGGCTCCGGTATG TGCAAGGC-3' and 5'-GCGGGCACGTTGAACGTCTC-3' from P. infestans (Latijnhouwers and Govers 2003)) was used as a control in PCR reactions. An additional control PCR without RT reaction was included. Relative quantification of the PCR products was obtained using ImageJ software.

\section{ACKNOWLEDGMENTS}

We thank S. Kamoun (The Sainsbury Laboratory, Norwich, U.K.) for providing P. capsici Avr3a-like clones (1 to 13), C. Smart and W. Fry (Department of Plant Pathology and Plant-Microbe Biology, Cornell University) for the $P$. capsici isolates used in this study and for helpful discussions, as well as R. Harris for $N$. repanda seeds. This work was supported by funds from the New York State Department of Agriculture and Markets.

\section{LITERATURE CITED}

Alfano, J. R., and Collmer, A. 2004. Type III secretion system effector proteins: Double agents in bacterial disease and plant defense. Annu. Rev. Phytopathol. 42:385-414.

Allen, R. L., Bittner-Eddy, P. D., Grenville-Briggs, L .J., Meitz, J. C., Rehmany, A. P., Rose, L. E., and Beynon, J. .L. 2004. Host-parasite coevolutionary conflict between Arabidopsis and downy mildew. Science 306:1957-1960

Armstrong, M. R., Whisson, S. C., Pritchard, L., Bos, J. I., Venter, E., Avrova, A. O., Rehmany, A. P., Bohme, U., Brooks, K., Cherevach, I., Hamlin, N., White, B., Fraser, A., Lord, A., Quail, M. A., Churcher, C., Hall, N., Berriman, M., Huang, S., Kamoun, S., Beynon, J. L., and Birch, P. R. 2005. An ancestral oomycete locus contains late blight avirulence gene Avr3a, encoding a protein that is recognized in the host cytoplasm. Proc. Natl. Acad. Sci. U.S.A. 102:7766-7771.

Ashfield, T., Ong, L. E., Nobuta, K., Schneider, C. M., and Innes, R. W. 2004. Convergent evolution of disease resistance gene specificity in two flowering plant families. Plant Cell 16:309-318.

Ausubel, F. M. 2005. Are innate immune signaling pathways in plants and animals conserved? Nat. Immunol. 6:973-979.

Baum, J. A., Bogaert, T., Clinton, W., Heck, G. R., Feldmann, P., Ilagan, O., Johnson, S., Plaetinck, G., Munyikwa, T., Pleau, M., Vaughn, T., and Roberts, J. 2007. Control of coleopteran insect pests through RNA interference. Nat. Biotechnol. 25:1322-1326.

Baumberger, N., Tsai, C. H., Lie, M., Havecker, E., and Baulcombe, D. C. 2007. The polerovirus silencing suppressor P0 targets ARGONAUTE proteins for degradation. Curr. Biol. 17:1609-1614.

Baxter, L., Tripathy, S., Ishaque, N., Boot, N., Cabral, A., Kemen, E., Thines, M., Ah-Fong, A., Anderson, R., Badejoko, W., Bittner-Eddy, P., Boore, J. L., Chibucos, M. C., Coates, M., Dehal, P., Delehaunty, K., Dong, S., Downton, P., Dumas, B., Fabro, G., Fronick, C., Fuerstenberg, S. I., Fulton, L., Gaulin, E., Govers, F., Hughes, L., Humphray, S., Jiang, R. H., Judelson, H., Kamoun, S., Kyung, K., Meijer, H., Minx, P., Morris, P., Nelson, J., Phuntumart, V., Qutob, D., Rehmany, A., RougonCardoso, A., Ryden, P., Torto-Alalibo, T., Studholme, D., Wang, Y. Win, J., Wood, J., Clifton, S. W., Rogers, J., Van den Ackerveken, G., Jones, J. D., McDowell, J. M., Beynon, J., and Tyler, B. M. 2010. Signatures of adaptation to obligate biotrophy in the Hyaloperonospora arabidopsidis genome. Science 330:1549-1551.

Bendahmane, A., Kanyuka, K., and Baulcombe, D. C. 1999. The Rx gene from potato controls separate virus resistance and cell death responses. Plant Cell 11:781-792.

Bendahmane, A., Querci, M., Kanyuka, K., and Baulcombe, D. C. 2000. Agrobacterium transient expression system as a tool for the isolation of disease resistance genes: Application to the Rx2 locus in potato. Plant J. 21:73-81.

Birch, P. R., Rehmany, A. P., Pritchard, L., Kamoun, S., and Beynon, J. L. 2006. Trafficking arms: Oomycete effectors enter host plant cells. Trends Microbiol. 14:8-11.

Bortolamiol, D., Pazhouhandeh, M., Marrocco, K., Genschik, P., and Ziegler-Graff, V. 2007. The polerovirus F box protein P0 targets ARGONAUTE1 to suppress RNA silencing. Curr. Biol. 17:1615-1621.

Bos, J. I. 2007. Page 181 in: Function, Structure and Evolution of the RXLR Effector AVR3a of Phytophthora infestans. PhD thesis. The Ohio State University, Columbus, OH, U.S.A.

Bos, J. I., Kanneganti, T. D., Young, C., Cakir, C., Huitema, E., Win, J., Armstrong, M. R., Birch, P. R., and Kamoun, S. 2006. The C-terminal half of Phytophthora infestans RXLR effector AVR3a is sufficient to trigger R3a-mediated hypersensitivity and suppress INF1-induced cell death in Nicotiana benthamiana. Plant J. 48:165-176.

Bos, J. I., Armstrong, M. R., Gilroy, E. M., Boevink, P. C., Hein, I., Taylor, R. M., Zhendong, T., Engelhardt, S., Vetukuri, R. R., Harrower, B., Dixelius, C., Bryan, G., Sadanandom, A., Whisson, S. C., Kamoun, S., and Birch, P. R. 2010. Phytophthora infestans effector AVR3a is essential for virulence and manipulates plant immunity by stabilizing host E3 ligase CMPG1. Proc. Natl. Acad. Sci. U.S.A. 107:9909-9914.

Boutemy, L. S., King, S. R., Win, J., Hughes, R. K., Clarke, T. A. Blumenschein, T. M., Kamoun, S., and Banfield, M. J. 2011. Structures of Phytophthora RXLR effector proteins: A conserved but adaptable fold underpins functional diversity. J. Biol. Chem. 286:35834-35842

Chisholm, S. T., Coaker, G., Day, B., and Staskawicz, B. J. 2006. Hostmicrobe interactions: Shaping the evolution of the plant immune response. Cell 124:803-814.

Collier, S. M., and Moffett, P. 2009. NB-LRRs work a "bait and switch" on pathogens. Trends Plant Sci. 14:521-529.

Csorba, T., Lozsa, R., Hutvagner, G., and Burgyan, J. 2010. Polerovirus protein P0 prevents the assembly of small RNA-containing RISC complexes and leads to degradation of ARGONAUTE1. Plant J. 62:463472 .

Dangl, J. L., and Jones, J. D. 2001. Plant pathogens and integrated defence responses to infection. Nature 411:826-833.

Dong, S., Qutob, D., Tedman-Jones, J., Kuflu, K., Wang, Y., Tyler, B. M., and Gijzen, M. 2009. The Phytophthora sojae avirulence locus Avr3c encodes a multi-copy RXLR effector with sequence polymorphisms among pathogen strains. PLoS One 4:e5556. Published online.

Dong, S., Yu, D., Cui, L., Qutob, D., Tedman-Jones, J., Kale, S. D., Tyler, B. M., Wang, Y., and Gijzen, M. 2011a. Sequence variants of the Phytophthora sojae RXLR effector Avr3a/5 are differentially recognized by Rps3a and Rps5 in soybean. PLoS One 6:e20172. Published online.

Dong, S., Yin, W., Kong, G., Yang, X., Qutob, D., Chen, Q., Kale, S. D., Sui, Y., Zhang, Z., Dou, D., Zheng, X., Gijzen, M., Tyler, B. M., and Wang, Y. 2011b. Phytophthora sojae avirulence effector Avr3b is a secreted NADH and ADP-ribose pyrophosphorylase that modulates plant immunity. PLoS Pathog 7:e1002353. Published online.

Dou, D., Kale, S. D., Wang, X., Jiang, R. H., Bruce, N. A., Arredondo, F. D., Zhang, X., and Tyler, B. M. 2008a. RXLR-mediated entry of Phytophthora sojae effector Avr1b into soybean cells does not require pathogen-encoded machinery. Plant Cell 20:1930-1947.

Dou, D., Kale, S. D., Liu, T., Tang, Q., Wang, X., Arredondo, F. D., Basnayake, S., Whisson, S., Drenth, A., Maclean, D., and Tyler, B. M. 2010. Different domains of Phytophthora sojae effector Avr4/6 are rec- 
ognized by soybean resistance genes Rps4 and Rps6. Mol. PlantMicrobe Interact. 23:425-435.

Dou, D., Kale, S. D., Wang, X., Chen, Y., Wang, Q., Wang, X., Jiang, R. H., Arredondo, F. D., Anderson, R. G., Thakur, P. B., McDowell, J. M., Wang, Y., and Tyler, B. M. 2008b. Conserved C-terminal motifs required for avirulence and suppression of cell death by Phytophthora sojae effector Avr1b. Plant Cell 20:1118-1133.

French-Monar, R. D., Jones, J. B., and Roberts, P. D. 2006. Characterization of Phytophthora capsici associated with roots of weeds on Florida vegetable farms. Plant Dis. 90:345-350.

Gilroy, E. M., Breen, S., Whisson, S. C., Squires, J., Hein, I., Kaczmarek, M., Turnbull, D., Boevink, P. C., Lokossou, A., Cano, L. M., Morales, J., Avrova, A. O., Pritchard, L., Randall, E., Lees, A., Govers, F., van West, P., Kamoun, S., Vleeshouwers, V. G., Cooke, D. E., and Birch, P. R. 2011. Presence/absence, differential expression and sequence polymorphisms between PiAVR2 and PiAVR2-like in Phytophthora infestans determine virulence on R2 plants. New Phytol. 191:763776

Gleave, A. P. 1992. A versatile binary vector system with a T-DNA organisational structure conducive to efficient integration of cloned DNA into the plant genome. Plant Mol. Biol. 20:1203-1207.

Gohre, V., and Robatzek, S. 2008. Breaking the barriers: Microbial effector molecules subvert plant immunity. Annu. Rev. Phytopathol. 46:189215 .

Grant, S. R., Fisher, E. J., Chang, J. H., Mole, B. M., and Dangl, J. L. 2006. Subterfuge and manipulation: Type III effector proteins of phytopathogenic bacteria. Annu. Rev. Microbiol. 60:425-449.

Grube, R. C., Radwanski, E. R., and Jahn, M. 2000. Comparative genetics of disease resistance within the solanaceae. Genetics 155:873-887.

Haas, B .J., Kamoun, S., Zody, M. C., Jiang, R. H., Handsaker, R. E., Cano, L. M., Grabherr, M., Kodira, C. D., Raffaele, S., Torto-Alalibo, T., Bozkurt, T. O., Ah-Fong, A. M., Alvarado, L., Anderson, V. L., Armstrong, M. R., Avrova, A., Baxter, L., Beynon, J., Boevink, P. C., Bollmann, S. R., Bos, J. I., Bulone, V., Cai, G., Cakir, C., Carrington, J. C. Chawner, M., Conti, L., Costanzo, S., Ewan, R., Fahlgren, N., Fischbach, M. A., Fugelstad, J., Gilroy, E. M., Gnerre, S., Green, P. J., Grenville-Briggs, L. J., Griffith, J., Grunwald, N. J., Horn, K., Horner, N. R., Hu, C. H., Huitema, E., Jeong, D. H., Jones, A. M., Jones, J. D., Jones, R. W., Karlsson, E. K., Kunjeti, S. G., Lamour, K., Liu, Z., Ma, L., Maclean, D., Chibucos, M. C., McDonald, H., McWalters, J., Meijer, H. J., Morgan, W., Morris, P. F., Munro, C. A., O’Neill, K., Ospina-Giraldo, M., Pinzon, A., Pritchard, L., Ramsahoye, B., Ren, Q., Restrepo, S., Roy, S., Sadanandom, A., Savidor, A., Schornack, S., Schwartz, D. C., Schumann, U. D., Schwessinger, B., Seyer, L., Sharpe, T., Silvar, C., Song, J., Studholme, D. J., Sykes, S., Thines, M., van de Vondervoort, P. J., Phuntumart, V., Wawra, S., Weide, R., Win, J., Young, C., Zhou, S., Fry, W., Meyers, B. C., van West, P., Ristaino, J., Govers, F., Birch, P. R., Whisson, S. C., Judelson, H. S., and Nusbaum, C. 2009. Genome sequence and analysis of the Irish potato famine pathogen Phytophthora infestans. Nature 461:393-398.

Hartman, G. L., and Huang, Y. H. 1993. Pathogenicity and virulence of Phytophthora capsici isolates from Taiwan on tomatoes and other selected hosts. Plant Dis. 77:588-591.

Hausbeck, M. K., and Lamour, K. H. 2004. Phytophthora capsici on vegetable crops: Research progress and management challenges. Plant Dis. 88:1292-1303.

Huang, G., Allen, R., Davis, E. L., Baum, T. J., and Hussey, R. S. 2006 Engineering broad root-knot resistance in transgenic plants by RNAi silencing of a conserved and essential root-knot nematode parasitism gene. Proc. Natl. Acad. Sci. U.S.A. 103:14302-14306.

Jones, J. D., and Dangl, J. L. 2006. The plant immune system. Nature 444:323-329

Judelson, H. S., and Tani, S. 2007. Transgene-induced silencing of the zoosporogenesis-specific NIFC gene cluster of Phytophthora infestans involves chromatin alterations. Eukaryot. Cell 6:1200-1209.

Kamoun, S. 2006. A catalogue of the effector secretome of plant pathogenic oomycetes. Annu Rev Phytopathol 44:41-60.

Lamour, K. H., Win, J., and Kamoun, S. 2007. Oomycete genomics: New insights and future directions. FEMS microbiology letters 274:1-8.

Lamour, K. H., Stam, R., Jupe, J., and Huitema, E. 2011. The oomycete broad-host-range pathogen Phytophthora capsici. Mol Plant Pathol.

Lamour, K. H., Stam, R., Jupe, J., and Huitema, E. 2012a. The oomycete broad-host-range pathogen Phytophthora capsici. Mol. Plant Pathol. $13: 329-337$

Lamour, K. H., Mudge, J., Gobena, D., Hurtado-Gonzales, O. P., Schmutz, J., Kuo, A., Miller, N. A., Rice, B. J., Raffaele, S., Cano, L. M., Bharti, A. K., Donahoo, R. S., Finley, S., Huitema, E., Hulvey, J., Platt, D., Salamov, A., Savidor, A., Sharma, R., Stam, R., Storey, D., Thines, M., Win, J., Haas, B. J., Dinwiddie, D. L., Jenkins, J., Knight, J. R., Affourtit, J. P., Han, C. S., Chertkov, O., Lindquist, E. A., Detter, C.,
Grigoriev, I. V., Kamoun, S., and Kingsmore, S. F. 2012b. Genome sequencing and mapping reveal loss of heterozygosity as a mechanism for rapid adaptation in the vegetable pathogen Phytophthora capsici. Mol. Plant-Microbe Interact. 25:1350-1360.

Latijnhouwers, M., and Govers, F. 2003. A Phytophthora infestans G-protein beta subunit is involved in sporangium formation. Eukaryot. Cell 2:971-977.

Mao, Y. B., Cai, W. J., Wang, J. W., Hong, G. J., Tao, X. Y., Wang, L. J. Huang, Y. P., and Chen, X. Y. 2007. Silencing a cotton bollworm P450 monooxygenase gene by plant-mediated RNAi impairs larval tolerance of gossypol. Nat. Biotechnol. 25:1307-1313.

Mazourek, M., Cirulli, E. T., Collier, S. M., Landry, L. G., Kang, B. C., Quirin, E. A., Bradeen, J. M., Moffett, P., and Jahn, M. 2009. The fractionated orthology of $\mathrm{Bs} 2$ and $\mathrm{Rx} / \mathrm{Gpa} 2$ supports shared synteny of disease resistance in the Solanaceae. Genetics 182:1351-1364.

McHale, L., Tan, X., Koehl, P., and Michelmore, R. W. 2006. Plant NBSLRR proteins: Adaptable guards. Genome Biol 7:212.

Morgan, W., and Kamoun, S. 2007. RXLR effectors of plant pathogenic oomycetes. Curr. Opin. Microbiol. 10:332-338.

Nowara, D., Gay, A., Lacomme, C., Shaw, J., Ridout, C., Douchkov, D., Hensel, G., Kumlehn, J., and Schweizer, P. 2010. HIGS: Host-induced gene silencing in the obligate biotrophic fungal pathogen Blumeria graminis. Plant Cell 22:3130-3141.

Nunes, C. C., and Dean, R. A. 2012. Host-induced gene silencing: A tool for understanding fungal host interaction and for developing novel disease control strategies. Mol. Plant Pathol. 13:519-529.

O'Connell, R. J., and Panstruga, R. 2006. Tete a tete inside a plant cell: Establishing compatibility between plants and biotrophic fungi and oomycetes. New Phytol. 171:699-718.

Oh, S. K., Young, C., Lee, M., Oliva, R., Bozkurt, T. O., Cano, L. M., Win, J., Bos, J. I., Liu, H. Y., van Damme, M., Morgan, W., Choi, D., Van der Vossen, E. A., Vleeshouwers, V. G., and Kamoun, S. 2009. In planta expression screens of Phytophthora infestans RXLR effectors reveal diverse phenotypes, including activation of the Solanum bulbocastanum disease resistance protein Rpi-blb2. Plant Cell 21:2928-2947.

Panwar, V., McCallum, B., and Bakkeren, G. 2013. Endogenous silencing of Puccinia triticina pathogenicity genes through in planta-expressed sequences leads to the suppression of rust diseases on wheat. Plant $\mathrm{J}$. 73:521-532.

Peart, J. R., Cook, G., Feys, B. J., Parker, J. E., and Baulcombe, D. C. 2002. An EDS1 orthologue is required for N-mediated resistance against tobacco mosaic virus. Plant J. 29:569-579.

Pfeffer, S., Dunoyer, P., Heim, F., Richards, K. E., Jonard, G., and ZieglerGraff, V. 2002. P0 of Beet Western yellows virus is a suppressor of posttranscriptional gene silencing. J. Virol. 76:6815-6824.

Qutob, D., Tedman-Jones, J., Dong, S., Kuflu, K., Pham, H., Wang, Y., Dou, D., Kale, S. D., Arredondo, F. D., Tyler, B. M., and Gijzen, M. 2009. Copy number variation and transcriptional polymorphisms of Phytophthora sojae RXLR effector genes Avr1a and Avr3a. PLoS One 4:e5066. Published online.

Rehmany, A. P., Gordon, A., Rose, L. E., Allen, R. L., Armstrong, M. R., Whisson, S. C., Kamoun, S., Tyler, B. M., Birch, P. R., and Beynon, J. L. 2005. Differential recognition of highly divergent downy mildew avirulence gene alleles by RPP1 resistance genes from two Arabidopsis lines. Plant Cell 17:1839-1850.

Schulze-Lefert, P., and Panstruga, R. 2011. A molecular evolutionary concept connecting nonhost resistance, pathogen host range, and pathogen speciation. Trends Plant Sci 16:117-125.

Segonzac, C., and Zipfel, C. 2011. Activation of plant pattern-recognition receptors by bacteria. Curr Opin Microbiol 14:54-61.

Sekine, K. T., Tomita, R., Takeuchi, S., Atsumi, G., Saitoh, H., Mizumoto, H., Kiba, A., Yamaoka, N., Nishiguchi, M., Hikichi, Y., and Kobayashi, K. 2012. Functional differentiation in the leucine-rich repeat domains of closely related plant virus-resistance proteins that recognize common avr proteins. Mol. Plant-Microbe Interact. 25:1219-1229.

Shan, W., Cao, M., Leung, D., and Tyler, B. M. 2004. The Avrlb locus of Phytophthora sojae encodes an elicitor and a regulator required for avirulence on soybean plants carrying resistance gene Rps1b. Mol. Plant-Microbe Interact. 17:394-403.

Soanes, D. M., and Talbot, N. J. 2008. Moving targets: Rapid evolution of oomycete effectors. Trends Microbiol. 16:507-510.

Song, T., Kale, S. D., Arredondo, F. D., Shen, D., Su, L., Liu, L., Wu, Y., Wang, Y., Dou, D., and Tyler, B. M. 2013. Two RxLR avirulence genes in Phytophthora sojae determine soybean Rpslk-mediated disease resistance. Mol. Plant-Microbe Interact. 26:711-720.

Thordal-Christensen, H. 2003. Fresh insights into processes of nonhost resistance. Curr. Opin. Plant Biol. 6:351-357.

Tian, D., and Babadoost, M. 2004. Host range of Phytophthora capsici from pumpkin and pathogenicity of the isolates. Plant Dis. 88:485-489.

Tinoco, M. L., Dias, B. B., Dall'Astta, R. C., Pamphile, J. A., and Aragao, 
F. J. 2010. In vivo trans-specific gene silencing in fungal cells by in planta expression of a double-stranded RNA. BMC Biol. 8:27.

Tomilov, A. A., Tomilova, N. B., Wroblewski, T., Michelmore, R., and Yoder, J. I. 2008. Trans-specific gene silencing between host and parasitic plants. Plant J. 56:389-397.

Tomita, R., Sekine, K. T., Mizumoto, H., Sakamoto, M., Murai, J., Kiba, A., Hikichi, Y., Suzuki, K., and Kobayashi, K. 2011. Genetic basis for the hierarchical interaction between Tobamovirus spp. and $L$ resistance gene alleles from different pepper species. Mol. Plant-Microbe Interact. 24:108-117.

Tyler, B. M., Tripathy, S., Zhang, X., Dehal, P., Jiang, R. H., Aerts, A., Arredondo, F. D., Baxter, L., Bensasson, D., Beynon, J. L., Chapman, J., Damasceno, C. M., Dorrance, A. E., Dou, D., Dickerman, A. W., Dubchak, I. L., Garbelotto, M., Gijzen, M., Gordon, S. G., Govers, F., Grunwald, N. J., Huang, W., Ivors, K. L., Jones, R. W., Kamoun, S., Krampis, K., Lamour, K. H., Lee, M. K., McDonald, W. H., Medina, M., Meijer, H. J., Nordberg, E. K., Maclean, D. J., Ospina-Giraldo, M. D., Morris, P. F., Phuntumart, V., Putnam, N. H., Rash, S., Rose, J. K. Sakihama, Y., Salamov, A. A., Savidor, A., Scheuring, C. F., Smith, B. M., Sobral, B. W., Terry, A., Torto-Alalibo, T. A., Win, J., Xu, Z., Zhang, H., Grigoriev, I. V., Rokhsar, D. S., and Boore, J. L. 2006. Phytophthora genome sequences uncover evolutionary origins and mechanisms of pathogenesis. Science 313:1261-1266.

van der Hoorn, R .A., and Kamoun, S. 2008. From guard to decoy: A new model for perception of plant pathogen effectors. Plant Cell 20:20092017.

van Poppel, P. M., Guo, J., van de Vondervoort, P. J., Jung, M. W., Birch, P. R., Whisson, S. C., and Govers, F. 2008. The Phytophthora infestans avirulence gene Avr4 encodes an RXLR-dEER effector. Mol. PlantMicrobe Interact. 21:1460-1470.

van West, P., Kamoun, S., van't Klooster, J. W., and Govers, F. 1999. Internuclear gene silencing in Phytophthora infestans. Mol. Cell 3:339-348.

Vetukuri, R. R., Avrova, A. O., Grenville-Briggs, L. J., van West, P., Soderbom, F., Savenkov, E. I., Whisson, S. C., and Dixelius, C. 2011. Evidence for involvement of Dicer-like, Argonaute and histone deacetylase proteins in gene silencing in Phytophthora infestans. Mol Plant Pathol. 12: 772-785.

Vleeshouwers, V. G., Rietman, H., Krenek, P., Champouret, N., Young, C., Oh, S. K., Wang, M., Bouwmeester, K., Vosman, B., Visser, R. G., Jacobsen, E., Govers, F., Kamoun, S., and Van der Vossen, E. A. 2008. Effector genomics accelerates discovery and functional profiling of potato disease resistance and phytophthora infestans avirulence genes. PLoS One 3:e2875. Published online.

Wesley, S. V., Helliwell, C. A., Smith, N. A., Wang, M. B., Rouse, D. T.,
Liu, Q., Gooding, P. S., Singh, S. P., Abbott, D., Stoutjesdijk, P. A. Robinson, S. P., Gleave, A. P., Green, A. G., and Waterhouse, P. M. 2001. Construct design for efficient, effective and high-throughput gene silencing in plants. Plant J. 27:581-590.

Whisson, S. C., Boevink, P. C., Moleleki, L., Avrova, A. O., Morales, J. G., Gilroy, E. M., Armstrong, M. R., Grouffaud, S., van West, P., Chapman, S., Hein, I., Toth, I. K., Pritchard, L., and Birch, P. R. 2007. A translocation signal for delivery of oomycete effector proteins into host plant cells. Nature 450:115-118.

Whisson, S. C., Avrova, A. O., van West, P., and Jones, J. T. 2005. A method for double-stranded RNA-mediated transient gene silencing in Phytophthora infestans. Mol. Plant Pathol. 6:153-163.

Win, J., Morgan, W., Bos, J., Krasileva, K. V., Cano, L. M., ChaparroGarcia, A., Ammar, R., Staskawicz, B. J., and Kamoun, S. 2007. Adaptive evolution has targeted the C-terminal domain of the RXLR effectors of plant pathogenic oomycetes. Plant Cell 19:2349-2369.

Win, J., Chaparro-Garcia, A., Belhaj, K., Saunders, D. G., Yoshida, K., Dong, S., Schornack, S., Zipfel, C., Robatzek, S., Hogenhout, S. A., and Kamoun, S. 2012. Effector biology of plant-associated organisms: Concepts and perspectives. Cold Spring Harb. Symp. Quant. Biol. 77:235247.

Wroblewski, T., Caldwell, K. S., Piskurewicz, U., Cavanaugh, K. A., Xu, H., Kozik, A., Ochoa, O., McHale, L. K., Lahre, K., Jelenska, J., Castillo, J. A., Blumenthal, D., Vinatzer, B. A., Greenberg, J. T., and Michelmore, R. W. 2009. Comparative large-scale analysis of interactions between several crop species and the effector repertoires from multiple pathovars of Pseudomonas and Ralstonia. Plant Physiol. 150:1733-1749.

Yaeno, T., Li, H., Chaparro-Garcia, A., Schornack, S., Koshiba, S., Watanabe, S., Kigawa, T., Kamoun, S., and Shirasu, K. 2011. Phosphatidylinositol monophosphate-binding interface in the oomycete RXLR effector AVR3a is required for its stability in host cells to modulate plant immunity. Proc. Natl. Acad. Sci. U.S.A. 108:14682-14687.

Yin, C., Jurgenson, J. E., and Hulbert, S. H. 2011. Development of a hostinduced RNAi system in the wheat stripe rust fungus Puccinia striiformis f. sp. tritici. Mol. Plant-Microbe Interact. 24:554-561.

Zipfel, C. 2009. Early molecular events in PAMP-triggered immunity. Curr. Opin. Plant Biol. 12:414-420

\section{AUTHOR-RECOMMENDED INTERNET RESOURCES}

Joint Genome Institute database: genome.jgi-psf.org mageJ software: imagej.nih.gov/ij 